\title{
Overtime and short-time with fluctuating absenteeism and demand
}

Citation for published version (APA):

de Regt, E. R. (2005). Overtime and short-time with fluctuating absenteeism and demand. METEOR, Maastricht University School of Business and Economics. METEOR Research Memorandum No. 027 https://doi.org/10.26481/umamet.2005027

Document status and date:

Published: 01/01/2005

DOI:

10.26481/umamet.2005027

Document Version:

Publisher's PDF, also known as Version of record

\section{Please check the document version of this publication:}

- A submitted manuscript is the version of the article upon submission and before peer-review. There can be important differences between the submitted version and the official published version of record.

People interested in the research are advised to contact the author for the final version of the publication, or visit the DOI to the publisher's website.

- The final author version and the galley proof are versions of the publication after peer review.

- The final published version features the final layout of the paper including the volume, issue and page numbers.

Link to publication

\footnotetext{
General rights rights.

- You may freely distribute the URL identifying the publication in the public portal. please follow below link for the End User Agreement:

www.umlib.nl/taverne-license

Take down policy

If you believe that this document breaches copyright please contact us at:

repository@maastrichtuniversity.nl

providing details and we will investigate your claim.
}

Copyright and moral rights for the publications made accessible in the public portal are retained by the authors and/or other copyright owners and it is a condition of accessing publications that users recognise and abide by the legal requirements associated with these

- Users may download and print one copy of any publication from the public portal for the purpose of private study or research.

- You may not further distribute the material or use it for any profit-making activity or commercial gain

If the publication is distributed under the terms of Article $25 \mathrm{fa}$ of the Dutch Copyright Act, indicated by the "Taverne" license above, 


\title{
Overtime and Short-time with Fluctuating Absenteeism and Demand *
}

\author{
Erik R. de Regt ${ }^{\dagger}$
}

24th August 2005

\begin{abstract}
Even though overtime is a widely observed phenomenon, this paper argues against the view of overtime as a structural cost minimizing labor demand solution. A large part of the observed overtime can be explained by the volatility of demand and absenteeism.

The paper's contribution is to investigate how stochastic absenteeism and stochastic demand tend to increase average hours per worker. Two distinct mechanisms are identified, independent of the type of uncertainty. The relative sizes of these mechanisms differ between the type of uncertainty, but also between cost minimization and profit maximization models. The profit maximization model has the advantage that it predicts a spike at normal hours.
\end{abstract}

JEL Classification: J22, J23

Keywords: Absenteeism, overtime, short-time, uncertainty, spike

${ }^{*}$ I would like to thank Lex Borghans, Joan Muysken and seminar participants at Maastricht University for useful comments on drafts of this paper. The usual disclaimer applies.

${ }^{\dagger}$ Department of Economics, Maastricht University, P.O. Box 616, 6200 MD Maastricht, the Netherlands. E-mail: e.deregt@algec.unimaas.nl. 
Overtime is a widely observed phenomenon. Average overtime hours are typically between $2.5 \%$ and $10 \%$ of normal hours. This often raises the question whether overtime hours could be transformed into regular jobs. In the US the focus of the debate is in terms of the statutory overtime premium, see Trejo (1993, 2003), whereas in Europe the debate centers around the European Working Time directive, see Bell and Hart (2003). Typically the economic analysis is then cast in a labor demand model, where firms demand structural overtime of their workers. Looking at the individual workers, however, the majority of workers does not work overtime. Moreover, management typically complains that it is the uncertainty in demand and in absenteeism that induce them to use overtime. ${ }^{1}$ In such an environment, policy measures aimed a reducing structural - i.e. non-stochastic cost minimizing - overtime seem to be misdirected.

The purpose of this paper is to analyze the impact of uncertainty in absence and demand on the overtime decision of firms. Starting from the basic labor demand model for workers and hours, the models allow for short-time and potential corner solutions without overtime. Moreover, stochastic variations in the attendance rate of its workers and in the demand for goods are included. The paper then identifies two different mechanisms leading to an increase in average hours per worker, inducing overtime. So to account for the observed overtime hours, we do not necessarily need to recur to models with non-stochastic cost minimizing demand for overtime.

Recently, Bell and Hart (2003) and Trejo (2003) also claim that the labor demand model may not be the most accurate model to analyze overtime issues. Their focus is quite different, however, as they do not specify the determinants of hours worked. Total remuneration and average hours are treated as fixed job characteristics, whereas the hourly wage is used as a compensating wage differential to accommodate changes in the underlying policy parameters, such as overtime premium or standard hours. The issue here is whether volatility in demand and attendance can explain the relatively high observed overtime figures.

The paper is most closely related to Ehrenberg (1970), who studied the impact of stochastic absenteeism on the demand for hours in a cost minimizing framework. He concluded that a stochastic employee absentee rate leads on average to a smaller amount of overtime per worker than in the case of a certainty absentee rate. This is the opposite of the conclusion reached here. The difference is based on two arguments. First, Ehrenberg (1970) did not prove that on average overtime declines, but instead showed that at the average absentee rate, overtime is smaller in the stochastic model compared to the certainty case. This remains true, and is also shown to hold for stochastic demand. However, as hours worked are a convex function of absenteeism, Jensen's inequality implies that expected overtime exceeds overtime at expected absenteeism. As a consequence, expected hours exceed the hours per worker in case of a certain rate of absenteeism. The second argument is new. Rather paradoxically, allowing for corner solutions, or even short-time, expected hours tend to increase even more. The reason is that at low rates of absenteeism or low demand, workers no longer work overtime, reducing the expected marginal cost of hours. This leads to substitution towards the intensive margin - hours worked - at the expense of the extensive margin - the number of employees. In a profit maximizing set-up, the lower effective premium also leads to a positive scale effect on employment, but that does not reverse the qualitative effect on expected hours.

The impact of demand uncertainty on employment and overtime has been studied by Ashworth et al. (1977) and Chen and Funke (2004). Even though both papers consider a demand constrained profit maximizing firm, their models are rather different and they reach different conclusions. Ashworth et al. (1977), treating workers and hours as perfect substitutes, conclude that an increase in volatility of demand might increase employment and thus reduce overtime, at least under some circumstances. In some sense this is a similar mechanism as the one identified

\footnotetext{
${ }^{1}$ For example, in a recent survey of Dutch firms in the metal-electro industry, see De Grip et al. (2003) for a description, only $10 \%$ of the firms indicated that they used structural overtime in 2002 , whereas $90 \%$ of the firms used overtime that year. The vast majority of firms indicated that fluctuations in demand were the main reasons for using overtime. Replacement for absenteeism was another important reason.
} 
by Ehrenberg (1970) for stochastic absenteeism. Chen and Funke (2004) suggest that hours increase and employment will fall due to increased demand volatility. Their results appear to be driven by intertemporal considerations, where due to firing and hiring costs, firms opt to wait in a more uncertain environment in order to reduce adjustment cost. ${ }^{2}$ My paper concentrates on the static demand for hours, with hours and workers being imperfect substitutes. In the cost minimization model demand is subject to random fluctuations, and the profit maximizing model considers a price taking firm where the price is subject to random fluctuations. The same two mechanisms as identified for stochastic absenteeism are at work for stochastic demand, but in different proportions.

Section 1 presents the two basic models under certainty; cost minimization and profit maximization. Section 2 considers the case of stochastic absenteeism and demand, concentrating on solutions in the overtime regime. This provides the first mechanism. Section 3 is then a brief intermezzo, pointing at the relevance of corner solutions and short-time. Section 4 allows for the possibility of a corner solution in the certainty case. Section 5 includes the possibility of corner solutions and short-time in the stochastic models. This provides the second mechanism. Moreover, the stochastic profit maximization model introduces a spike at normal hours. Section 6 concludes.

\section{Overtime and certain absenteeism}

\subsection{Cost minimization}

Consider a cost minimizing firm choosing the best combination of employees $n$ and hours per employee $h$, knowing that only a fraction $a$ of its employees will be attending during a typical day. Labor services $\ell$ are given by a Cobb-Douglas function

$$
\ell=a^{1 / \tau} n h^{\gamma} . \quad 0<\tau \leq 1,0<\gamma<1
$$

Underlying this expression is a labor services function where workers and hours are imperfect substitutes: first of all, there are decreasing returns to weekly hours of work $h$, as $\gamma<1 ;^{3}$ secondly, teamwork effects may be present leading to increasing returns to attendance $a$ when $\tau<1 .{ }^{4}$ Coles and Treble (1996), for example, argue that assembly line technologies also lead to nondecreasing returns to attendance. Allen (1983) provides evidence in favor of increasing returns to attendance.

For simplicity, ignore capital services, and let there be decreasing returns to labor services. ${ }^{5}$ Let $q$ denote the output level, and let $q=\ell^{\alpha}$, with $0<\alpha<1$, then the production function can we written as

$$
q=a^{\alpha / \tau} n^{\alpha} h^{\alpha \gamma}
$$

Ehrenberg (1970) used a similar Cobb-Douglas production function to obtain specific results, but without teamwork effects $(\tau=1)$.

Labor costs consist of various parts. First, attending employees working the normal workweek $\bar{h}$ get a hourly wage of $w$. Both are exogenously given for the firm. When working overtime,

\footnotetext{
${ }^{2}$ Moreover, their CES production function appears to be flawed, as even in the long-run hours per worker are not invariant to scale.

${ }^{3}$ This condition corresponds to the second-order condition for cost minimization.

${ }^{4}$ More specifically, consider the CES labor services function $\ell / n=\left(\sum_{i=1}^{n} \frac{1}{n} h_{i}^{\gamma \tau}\right)^{1 / \tau}$, with $0<\tau \leq 1$. To allow for absence we need the condition $\tau>0$, otherwise each individual worker would be essential in the production process. Teamwork is important when hours worked by different workers are no perfect substitutes, that is for $\tau<1$. Absent workers have $h_{i}=0$, whereas attending workers all work the same amount of hours $h_{i}=h$.

${ }^{5}$ Including capital services in a simple model of hours demand does not alter the main conclusion of the paper, see de Regt (2005a).
} 
that is when $h>\bar{h}$, employees get an overtime premium $\theta>0$. Legislated overtime premiums, if existent, are typically in the order of 25 to 50\%, see Hart (2004) and OECD (1998). By now it is well documented that firms face quasi-fixed costs beside the hourly wage costs, see e.g. Hart (1984) or Hamermesh (1993) for overviews. These quasi-fixed costs do not vary with the length of the workweek, but may depend on attendance $a$. Let $v$ denote the fixed costs per employee, independent of attendance. Sick pay, on the other hand, is only paid to absent workers. They get a fraction $\rho, 0 \leq \rho<1$, of normal pay $w \bar{h}$. Thus absent workers get no overtime premium, even if overtime was scheduled. In the Netherlands, for example, firms must continue to pay at least $70 \%$ of the normal salary of sick employees during the first year of sickness, implying $\rho=0.7$. Combining these terms, total labor costs can be written as

$$
C=\{v+\rho(1-a) w \bar{h}+a w[\bar{h}+(1+\theta)(h-\bar{h})]\} n .
$$

This corresponds to the specification used by Ehrenberg (1970). In fact this equation only holds for $h>\bar{h}$, but as in Ehrenberg this restriction will be ignored until Section 3, assuming that the solution entails overtime. Indeed, aggregate data always report positive overtime, although this may also be due to the fact that short-time is typically underreported, if reported at all.

Using the production function (1) to substitute out employment $n$, the first-order condition for cost minimization can easily be written as

$$
a w(1+\theta) h=\gamma\{v+\rho(1-a) w \bar{h}+a w[-\theta \bar{h}+(1+\theta) h]\} .
$$

Accordingly, optimal hours are given as

$$
h^{*}=\frac{\gamma}{1-\gamma} \frac{z-\theta}{1+\theta} \equiv f(z, \theta) \bar{h}
$$

where

$$
z \equiv \frac{v+\rho(1-a) w \bar{h}}{a w \bar{h}} .
$$

The variable $z$ represents fixed labor costs as a fraction of normal wage costs of attending workers. It summarizes the relative price effects at the intensive and extensive margins, except for the impact of the overtime premium $\theta$. An increase in $z$ corresponds to a relative increase of the costs at the extensive margin, and thus leads towards a substitution in the direction of more hours worked and less employees. This may be due to an increase in non-wage costs $v$, higher sick-pay $\rho$ or higher absenteeism $(1-a) .{ }^{6}$ The overtime premium $\theta$ unambiguously reduces hours worked per employee. First, the premium increases the marginal costs of hours, this is reflected in the denominator of $f(z, \theta)$. Moreover, a higher premium reduces the fixed cost of attending employees by $-\theta w \bar{h}$, as reflected in the numerator of $f(z, \theta)$. Finally, shifts in demand $q$ do not affect hours demand. ${ }^{7}$

Substitution of optimal hours $h^{*}$ in the production function (1) gives the optimal number of employees $n_{c}^{c}$ with a certain demand $q$ and attendance rate $a^{8}$

$$
n_{c}^{c}=q^{1 / \alpha} a^{-1 / \tau} \bar{h}^{-\gamma} f(z, \theta)^{-\gamma} .
$$

As in Ehrenberg (1970) an increase in absenteeism, or a decrease in attendance $a$, leads to a scale effect at fixed output levels and a substitution effect through $z$. Both effects work in

\footnotetext{
${ }^{6}$ Yaniv (1995) extended the model to incorporate a feedback of overtime to absenteeism. Excessive overtime increases the probability of burnout, and hence might be a cause of absenteeism. This is ignored here.

${ }^{7}$ In a model with capital services, this property vanishes in the short run, except when the substitution elasticity between capital and labor is unity, see de Regt (2005a).

${ }^{8}$ The superscript $c$ in $n_{c}^{c}$ refers to the cost minimizing solution, the subscript $c$ refers to the certainty case. Lateron, the superscript $p$ will be used for profit maximization and the subscript $u$ for uncertainty.
} 
opposite direction. Whether the scale effect of lower attendance at fixed output levels dominates the substitution effect depends on teamwork effects $\tau$ and on the relative price $z$. Indeed, the elasticity of employment with respect to attendance is

$$
\frac{\partial \ln n_{c}^{c}}{\partial \ln a}=-\frac{1}{\tau}+\gamma \frac{z+\rho}{z-\theta} .
$$

When $z$ is sufficiently large, for example when absenteeism is high, an increase in the certainty absence rate, thus a decrease in $a$, increases hours worked but also tends to lead to a larger employment level through the scale effect. The scale effect increases when teamwork effects are stronger, that is for low $\tau$.

\subsection{Profit maximization}

Next consider a profit maximizing firm. Having decreasing returns employment $n$, I consider a price taking firm. Let $p$ denote the exogenous price faced by by the firm, then, using the production function (1) and the definition of $z$, profits $\pi$ can be written as

$$
\pi=p a^{\alpha / \tau} n^{\alpha} h^{\alpha \gamma}-a w[(z-\theta) \bar{h}+(1+\theta) h] n .
$$

Maximizing profits with respect to hours $h$ and employment $n$ gives the first-order conditions

$$
\begin{gathered}
0=\frac{\partial \pi}{\partial n}=\alpha p a^{\alpha / \tau} n^{\alpha-1} h^{\alpha \gamma}-a w[(z-\theta) \bar{h}+(1+\theta) h] \\
0=\frac{\partial \pi}{\partial h}=\alpha \gamma p a^{\alpha / \tau} n^{\alpha} h^{\alpha \gamma-1}-a w(1+\theta) n .
\end{gathered}
$$

Solving for hours gives the scale invariant $h^{*}=f(z, \theta) \bar{h}$ as before, whereas the profit maximizing employment level $n_{c}^{p}$ is given by

$$
n_{c}^{p}=\left(\frac{\alpha \gamma p a^{(\alpha-\tau) / \tau}}{(1+\theta) w f(z, \theta)^{1-\alpha \gamma} \bar{h}^{1-\alpha \gamma}}\right)^{1 /(1-\alpha)} .
$$

The comparative statics are standard, except perhaps for two variables. Differentiating (6) gives

$$
\frac{\partial \ln n_{c}^{p}}{\partial \theta}=\frac{\alpha(1-\gamma)}{(1-\alpha)(z-\theta)}\left(\frac{1-\alpha \gamma}{\alpha(1-\gamma)}-f(z, \theta)\right)
$$

and

$$
\frac{\partial \ln n_{c}^{p}}{\partial \ln a}=\frac{\alpha-\tau}{\tau(1-\alpha)}+\frac{1-\alpha \gamma}{1-\alpha} \frac{z+\rho}{z-\theta}>\frac{\alpha(1-\tau \gamma)}{\tau(1-\alpha)}>0 .
$$

The impact of the overtime premium $\theta$ is ambiguous. A higher overtime premium decreases employment when optimal hours are long, that is for $h^{*}>\frac{1-\alpha \gamma}{\alpha(1-\gamma)} \bar{h}>\bar{h}$, but increases employment for lower levels of overtime. For reasonable values of the parameters, the latter case is most likely. The impact of absenteeism on employment is unambiguous, however. Higher attendance $a$ increases employment, as contrary to the cost minimizing solution the ambiguous scale effect is always dominated by the substitution effect.

\section{Stochastic absenteeism and demand}

In contrast to the previous section, let attendance $a$ vary stochastically over its domain $[0,1]$, with expected value $E(a)$. Correspondingly, the relative cost $z$ is redefined at expected attendance $E(a)$. Similarly, let demand $q>0$ be a stochastic variable with expected value $E(q)$ in the 
cost minimization model, or let the price $p>0$ be stochastic with expected value $E(p)$ for the profit maximization model. The corresponding solutions for employment in the certainty case (4) and (6) are evaluated at these expected values. For simplicity, let absenteeism and demand (or price) be uncorrelated. ${ }^{9}$

The timing of the firm's decisions is that workers are to be hired before the stochastic variables are revealed, but hours can be adjusted after the shocks have realized. Therefore, actual hours are no longer scale independent in the short-run.

\subsection{Cost minimization}

To solve the stochastic cost minimizing model, invert the production function (1) to obtain constrained hours as

$$
h^{c}=q^{1 / \alpha \gamma} a^{-1 / \tau \gamma} n^{-1 / \gamma}
$$

Substituting out hours from labor costs expected costs, using the definition of $z$, can be written as

$$
E(C)=(z-\theta) E(a) w \bar{h} n+(1+\theta) w E\left(q^{1 / \alpha \gamma} a^{-(1-\tau \gamma) / \tau \gamma}\right) n^{-(1-\gamma) / \gamma} .
$$

Minimizing this with respect to employment $n$ gives the employment level

$$
n_{u}^{c}=E\left(q^{1 / \alpha \gamma}\right)^{\gamma} E\left(a^{-(1-\tau \gamma) / \tau \gamma}\right)^{\gamma} E(a)^{-\gamma} \bar{h}^{-\gamma} f(z, \theta)^{-\gamma}
$$

Comparing this expression with the solution under certainty (4) gives

$$
\frac{n_{u}^{c}}{n_{c}^{c}}=\delta_{n}^{c} \equiv\left(\frac{E\left(q^{1 / \alpha \gamma}\right)}{E(q)^{1 / \alpha \gamma}} \frac{E\left(a^{-(1-\tau \gamma) / \tau \gamma}\right)}{E(a)^{-(1-\tau \gamma) / \tau \gamma}}\right)^{\gamma} .
$$

The parameter $\delta_{n}^{c}$ summarizes the impact of stochastic variations in demand and absenteeism on employment. The impact of absenteeism is somewhat different, because it also directly influences costs. The result is given as:

Proposition 1 In a cost minimizing framework with fixed premium rate $\theta$, random absenteeism and random demand lead to a larger pool of employees, as $\delta_{n}^{c}>1$.

Proof. See Appendix A.

For absenteeism, this was the effect identified by Ehrenberg (1970), see also Hart (2004). The intuition is the following. For a given number of employees, random variations in absenteeism lead to higher expected hours, and thus to higher expected costs, compared to the hours at certain absenteeism and demand. The optimal response of the firm is to increase the number of employees. As the proposition illustrates, as similar effect occurs for demand uncertainty. There is one difference, however. The impact of demand works solely through the production function, whereas attendance also directly affects labor costs. This explains the different structure of the production function parameters in $\delta_{n}^{c}$.

As the production function is unchanged, the mirror image is that conditional hours - that is hours given the expected value of absenteeism and demand - decline. Indeed, substituting $n_{u}^{c}$ in (7), conditional cost minimizing hours are given by

$$
\left.h^{c}\right|_{q=E(q), a=E(a)}=\delta_{n}^{c^{-1 / \gamma}} h^{*}<h^{*} .
$$

\footnotetext{
${ }^{9}$ The empirical evidence points to a positive correlation between absenteeism and the business cycle, however, see Audas and Goddard (2001) for a recent study.
} 
This led Ehrenberg (1970) to conclude that stochastic absenteeism tends to reduce hours worked. But given the convex relation between hours worked and absenteeism or demand, expected hours are larger than conditional hours. Using equation (7) and taking expectations gives

$$
\frac{E\left(h^{c}\right)}{h^{*}}=\delta_{h}^{c} \equiv \frac{E(a) E\left(a^{-1 / \tau \gamma}\right)}{E\left(a^{-(1-\tau \gamma) / \tau \gamma}\right)}
$$

where $\delta_{h}^{c}$ summarizes the impact of stochastic variations in demand and absenteeism on hours worked. This yields the following result.

Proposition 2 In a cost minimizing framework with fixed premium rate $\theta$, random absenteeism increases expected hours above the certainty level, as $\delta_{h}^{c}>1$. Random demand does not affect expected hours.

\section{Proof. See Appendix A.}

Stochastic variations in demand do not affect expected hours, even though conditional hours decline. The increase in expected hours due to the convex relation between hours worked and demand is exactly offset by the negative effect through increased employment. This reflects the fact that equilibrium hours $h^{*}$ are scale independent. For absenteeism, however, the additional impact on labor costs leads to an increase in expected hours. Thus Ehrenberg's original conclusion is reversed: random absenteeism increases average hours.

\subsection{Profit maximization}

In the profit maximizing model hours worked are set ex post according to the first-order condition (5b). Solving for hours worked, this yields

$$
h^{p}=\left(\frac{\alpha \gamma p a^{(\alpha-\tau) / \tau} n^{-(1-\alpha)}}{(1+\theta) w}\right)^{1 /(1-\alpha \gamma)} .
$$

A higher price $p$ increases hours worked, as it increases marginal revenue. Attendance $a$ also increases marginal revenue, but at the same time it increases marginal costs. Hence the impact is ambiguous. With weak teamwork effects $(\tau>\alpha)$ the cost effect dominates and higher attendance reduces hours worked. But hours worked increase when teamwork effects are stronger $(\tau<\alpha)$.

Using the envelope theorem, the expected profit maximizing employment level is set as

$$
0=\frac{\partial E(\pi)}{\partial n}=E\left(\alpha p a^{\alpha / \tau} h^{p^{\alpha \gamma}} n^{\alpha-1}\right)-w\left[(z-\theta) E(a) \bar{h}+(1+\theta) E\left(a h^{p}\right)\right] .
$$

Substituting (10) and solving, the optimal employment level under uncertainty is

$$
n_{u}^{p}=\left(\frac{\alpha \gamma E\left(p^{\frac{1}{1-\alpha \gamma}}\right)^{1-\alpha \gamma} E\left(a^{\frac{\alpha(1-\tau \gamma)}{\tau(1-\alpha \gamma)}}\right)^{1-\alpha \gamma}}{(1+\theta) w E(a)^{1-\alpha \gamma} f(z, \theta)^{1-\alpha \gamma} \bar{h}^{1-\alpha \gamma}}\right)^{1 /(1-\alpha)}
$$

Comparing with the solution under certainty (6) gives

$$
\frac{n_{u}^{p}}{n_{c}^{p}}=\delta_{n}^{p} \equiv\left(\frac{E\left(p^{\frac{1}{1-\alpha \gamma}}\right)^{1-\alpha \gamma}}{E(p)} \frac{E\left(a^{\frac{\alpha(1-\tau \gamma)}{\tau(1-\alpha \gamma)}}\right)^{1-\alpha \gamma}}{E(a)^{\alpha(1-\tau \gamma) / \tau}}\right)^{1 /(1-\alpha)}
$$

where the parameter $\delta_{n}^{p}$ gives the impact of stochastic variations in demand and absenteeism on employment. Proposition 3 summarizes. 
Proposition 3 In a profit maximizing framework with fixed premium rate $\theta$,

- random demand leads to a larger pool of employees,

- random absenteeism leads to

- a smaller pool of employees when teamwork effects are weak $(\tau>\alpha)$,

- a larger pool of employees when teamwork effects are strong $(\tau<\alpha)$.

Proof. See Appendix A.

Compared to the cost minimizing firm, see Proposition 1, there is an additional scale effect. With weak teamwork effects, absenteeism and hours are positively related, recall equation (10). As the relation is convex in this case, stochastic absenteeism will increase hours at given employment level, increasing production costs. As a result, the profit maximizing output and employment levels fall. This effect dominates the positive effect on employment in the cost minimizing firm. When teamwork effects are stronger, the correlation between absenteeism and hours becomes negative, see equation (10). This reduces the negative scale effect, and employment increases as for a cost minimizing firm.

The mirror image of the changed employment level is the change in conditional hours. Substituting employment (11) in the hours equation (10), and evaluating this at expected price and attendance gives

$$
\left.h^{p}\right|_{p=E(p), a=E(a)}=\delta_{n}^{p^{-\frac{1-\alpha}{1-\alpha \gamma}}} h^{*} .
$$

So when employment increases, due to for example random demand, conditional hours fall. However, taking expectations of the hours equation (10), expected hours are given as

$$
\frac{E\left(h^{p}\right)}{h^{*}}=\delta_{h}^{p} \equiv \frac{E(a) E\left(a^{\frac{\alpha-\tau}{\tau(1-\alpha \gamma)}}\right)}{E\left(a^{\frac{\alpha(1-\tau \gamma)}{\tau(1-\alpha \gamma)}}\right)},
$$

where the parameter $\delta_{h}^{p}$ gives the impact of stochastic variations in demand and absenteeism on hours worked. Proposition 4 summarizes.

Proposition 4 In a profit maximizing framework with fixed premium rate $\theta$,

- random demand does not affect expected hours,

- random absenteeism

- increases expected hours when teamwork effects are weak $(\tau>\alpha)$,

- reduces expected hours when teamwork effects are strong $(\tau<\alpha)$.

Proof. See Appendix A.

As before, random demand - or price in this case - does not affect average hours. But, whereas the cost minimizing model predicts an increase in expected hours due to random absenteeism, the sign of the effect may vary according to the production technology in the profit maximizing model. With weak teamwork effects, stochastic variations in absenteeism increase expected hours, but with strong teamwork effects expected hours will be reduced, as predicted by Ehrenberg (1970), but for a rather different reason. 
Table 1: Overtime and stochastic demand

\begin{tabular}{lll}
\hline$\sigma$ & 0.1 & 0.2 \\
\hline$\delta_{h}^{c}=\delta_{h}^{p}$ & 1. & 1. \\
$\delta_{n}^{c}$ & 1.006 & 1.023 \\
$\delta_{n}^{p}$ & 1.021 & 1.089 \\
\hline
\end{tabular}

\subsection{Numerical example}

Although the sign of the impact of stochastic absenteeism and demand has been identified, the size of the effects is not clear yet. A numerical illustration may provide some indication. Two sets of parameters determine the size of the impact: first, parameters from the production functions; and second, the parameters of the distribution of attendance and demand.

To start with the first, returns to employment $\alpha$ roughly correspond to the share of labor. So $\alpha=0.7$ seems rather innocuous. Hart (2004) provides an overview of the estimates of the returns to hours $\alpha \gamma$. This parameter is not very precisely estimated, but returns to hours seem to be somewhat smaller than returns to employment. I set $\gamma=0.8$, somewhat lower than the 0.9 used by Chen and Funke (2004), but slightly higher than the 0.75 used by Ortega (2003). Allen (1983) estimated increasing returns to attendance in the US, this can be used to determine the teamwork parameter $\tau$. Three broad alternatives will be considered: no teamwork, $\tau=1$, weak teamwork $\tau=0.8$, and strong teamwork effects $\tau=0.6$. The latter two are broadly consistent with Allen's (1983) estimates. ${ }^{10}$

With respect to the distribution of of firm-specific demand $q$ or price $p$, it is assumed that these two variables have lognormal distributions. Their means do not affect the $\delta$ 's, nor the expected hours worked, but only the employment level. Chen and Funke (2004) use $\sigma_{q}=0.12$ as their baseline for the standard deviation of demand, varying from 0.08 to $0.18 .{ }^{11}$ More or less similarly, I use two values, $\sigma=0.1$ and $\sigma=0.2$, for the standard deviation of both (log) demand and (log) price. As absenteeism typically has a rather skew distribution, it is assumed that attendance is distributed according to a Beta-distribution, as in Allen (1983). Mean attendance $E(a)$ is set at 0.95 , implying a reasonable $5 \%$ average rate of absenteeism. Allen (1983) estimates the variance of absenteeism - and thus of attendance - to be somewhere between 0.016 and 0.034. The higher variance implies a rather unlikely U-shaped density function, with clusters around zero and one. So I concentrate on lower variance levels, with $\sigma_{a}^{2}=0.01$ and $\sigma_{a}^{2}=0.015$, respectively. ${ }^{12}$

Table 1 gives the impact of demand uncertainty on the demand for hours and employment. The impact is independent of the teamwork parameter $\tau$, as can be seen looking at the definitions of the $\delta$ 's. Demand uncertainty does not affect expected hours, but increases the employment level by $0.6 \%$ to almost $9 \%$. The impact increases with the standard deviation, as was to be expected. Moreover, the impact is stronger in the profit maximizing model than in the cost minimizing model, but this could just reflect the fact that the standard variation of prices is perhaps smaller than the standard variation of output, as would be the consequence of an elastic demand curve.

Table 2 gives the impact of stochastic absenteeism on the demand for hours and employment.

\footnotetext{
${ }^{10}$ The labor services specification used by Allen (1983) is $\ell=(1-a)^{-\beta} a n h$. So the elasticity of labor services with respect to attendance $a$ is $\frac{\partial \ln \ell}{\partial \ln a}=1+\beta \frac{a}{1-a}$. Two estimates of $\beta$ are presented: 0.019 and 0.046 ; where the lower value is considered to be more reasonable. As $\frac{\partial \ln \ell}{\partial \ln a}=\frac{1}{\tau}$ in my specification, this can be used to infer the teamwork parameter $\tau$. With mean attendance of 0.95 , the corresponding values for $\tau$ are 0.73 and 0.53 .

${ }^{11}$ Using a uniform distribution, Ortega (2003) utilizes a fairly high coefficient of variation of 0.5.

${ }^{12}$ Let $a \sim B\left(b_{1}, b_{2}\right)$ denote the Beta distribution of attendance, then the parameters $\left(b_{1}, b_{2}\right)$ are given by $(3.563,0.188)$ for low variance and $(2.058,0.108)$ for the high variance case. Both sets of parameters imply a unimodal J-shaped density function clustered near one.
} 
Table 2: Overtime and stochastic absenteeism

\begin{tabular}{lcccccc}
\hline$\tau$ & \multicolumn{2}{c}{1} & \multicolumn{2}{c}{0.8} & \multicolumn{2}{c}{0.6} \\
$\sigma_{a}^{2}$ & 0.01 & 0.015 & 0.01 & 0.015 & 0.01 & 0.015 \\
\hline$\delta_{h}^{c}$ & 1.027 & 1.077 & 1.039 & 1.158 & 1.070 & 3.167 \\
$\delta_{n}^{c}$ & 1.002 & 1.004 & 1.006 & 1.013 & 1.018 & 1.045 \\
\hline$\delta_{h}^{p}$ & 1.012 & 1.025 & 1.004 & 1.008 & 0.995 & 0.992 \\
$\delta_{n}^{p}$ & 0.998 & 0.996 & 0.998 & 0.997 & 1.005 & 1.007 \\
\hline
\end{tabular}

In the cost minimizing model, the effect on hours is strongly influenced by both the variance of attendance and the teamwork parameter. Without any teamwork effects, expected hours increase by $3 \%$ to $7 \%$, depending on the variance of attendance. With weak teamwork effects, expected hours increase even by $4 \%$ to $16 \%$, and with strong teamwork effects they would increase unrealistically by more than $300 \%$ in case of high variance. At the same time employment would increase by almost $5 \%$ in the latter case. For weaker teamwork effects, employment is increasing only very little.

In the profit maximizing model, the effects on expected hours are smaller. In line with Propositions 3 and 4, hours increase and employment decreases with weak or no teamwork effects, and vice versa for strong teamwork. The effects remain limited, however.

What explains the large differences in expected hours between the cost minimizing and profit maximizing models? Ashworth et al. (1977) concluded that overtime is mostly a response to too little, instead of too much, demand, as a profit maximizing firm can simply decide to supply less than demand when demand is high. Similarly in terms of absenteeism, a profit maximizing firm can simply decide to supply less when absenteeism is high, whereas a cost minimizing firm should always satisfy demand and increase hours.

The international overview of Hart (2004) reveals that average overtime hours vary between one to four hours per week. With a normal workweek of about 40 hours, this amounts to $2.5 \%$ to $10 \%$ of normal hours, as mentioned in the introduction. Table 2 seems to suggest that fluctuations in absenteeism can only explain part of the observed overtime hours, at least in the profit maximizing model. Rather paradoxically, the following sections will argue that the possible occurrence of short-time may provide a further explanation for observed overtime.

\section{The relevance of normal hours and short-time}

Although overtime is an important phenomenon, only a (large) minority of employees does work more than normal hours. For the US, DeLeire, Bhattacharva et al. (2002) report overtime incidence of around $12 \%$ for all workers and $19 \%$ for production workers in manufacturing. This is somewhat lower than earlier estimates in Trejo (1993). Friesen (2002) reports that in 1997 in Canada only $9 \%$ of the jobs usually required overtime. According to Kalwij and Gregory (2003) one-third of male employees in the UK work paid overtime. This is slightly higher than the $20 \%$ in 1993 for Germany or the UK documented by Bell, Hart et al. (2000). ${ }^{13}$ Hart (2004) provides some further evidence, including unpaid overtime.

Additionally, Ortega (2003) presents evidence of sizeable spikes at normal hours: in the US, about one third of the employees were working exactly 40 hours in 2002; in France about $40 \%$ of the employees were exactly working the 39 hours legal workweek in 1999; and in the unregulated UK peaks of 10 to $20 \%$ were observed for 37 to 40 hours in 1991. Beside these spikes, Ortega's figures also illustrate that there are numerous workers working less than normal hours. Partly

\footnotetext{
${ }^{13}$ The evidence of the Dutch statistical bureau suggests that paid overtime incidence in the Netherlands is only about $10 \%$.
} 
this will be due to part-time work, but we can not eliminate the possibility that some of them work short-time. Indeed, Van Audenrode (1994) has established the importance of short-time compensation systems in Europe. Countries with generous short-time compensation programs have larger hours responses to downward variations in the need for labor. However, it is difficult to obtain data about short-time working.

These observations point at two weaknesses of the previous models: first, they do not allow for corner solutions and short-time; and second, they do not distinguish between overtime incidence and hours worked by overtime workers. In de Regt (2005b) I develop a model with overtime incidence and hours worked by overtime workers and show that overtime hours and overtime incidence are typically positively related. Thus focussing only on hours worked can be viewed as reduced form analysis. Therefore, this paper just focusses on the first issue, and allows for the possibility of no overtime. This will lead to additional effects of uncertainty.

\section{A corner solution with certainty}

To accommodate the possibility of corner solutions and short-time, the cost structure has to be modified. In the previous sections, as in Ehrenberg's original model, no distinction was made between solutions with and without overtime. All hours command the same premium $\theta>0$. However, when hours worked fall below standard hours $\bar{h}$, no overtime premium is paid anymore and the compensation schedule should not fail to incorporate this. To do so, let $w o(h)$ denote the remuneration of attending workers. The compensation schedule $o(h)$ thus summarizes the compensation of hours. The schedule with a fixed overtime premium $\theta$ used up to here was

$$
o(h)=\bar{h}+\theta(h-\bar{h})=-\theta \bar{h}+(1+\theta) h .
$$

A straightforward generalization incorporating short-time and overtime is the kinked schedule

$$
o(h)=\bar{h}+\max \left(\theta_{s}(h-\bar{h}), \theta_{o}(h-\bar{h})\right) . \quad-1 \leq \theta_{s} \leq 0<\theta_{o}
$$

For overtime hours $h>\bar{h}$ the firm pays a fixed overtime premium $\theta=\theta_{o}$, as before, but if hours worked fall below standard hours, the firm pays an short-time premium $\theta=\theta_{s}$. This may be due to institutional or contractual arrangements, such as short-time rules, etc. For $\theta_{s}=0$, the marginal cost of an additional hour below standard hours is just the hourly wage $w$, as in Chen and Funke (2004), Ortega (2003) and Trejo (2003). However, when $\theta_{s}=-1$ as in Ahsworth et al. (1977), institutional arrangements force the firm to pay the normal standard pay $w \bar{h}$ even when less hours are worked. Intermediate cases of generosity of short-time compensation may be relevant, see Van Audenrode (1994). ${ }^{14}$

Solving the certainty models with the kinked compensation schedule (14) is rather straightforward. First, solve the model for a fixed premium rate $\theta$, being either $\theta_{o}$ or $\theta_{s}$. The corresponding solution is $h=f(z, \theta) \bar{h}$, as before. As hours worked are decreasing in the premium $\theta$, $f\left(z, \theta_{o}\right)<f\left(z, \theta_{s}\right)$. Three mutually exclusive cases can be distinguished: first, when $f\left(z, \theta_{o}\right)>1$, the solution entails structural overtime; second, for $f\left(z, \theta_{s}\right)<1$, normal hours are too long and there is structural short-time; the remaining intermediate case is $f\left(z, \theta_{o}\right)<1<f\left(z, \theta_{s}\right)$, leading to the corner solution $h=\bar{h}$. What regime prevails thus depends on the fixed costs $z$ in relation to the overtime and short-time premiums.

Another way to characterize the solution will be useful lateron. As hours worked are decreasing in the premium $\theta$, there is a unique premium rate $\bar{\theta}$ leading exactly to the corner solution

\footnotetext{
${ }^{14}$ There may a be a link between the sick replacement rate $\rho$ and the undertime premium $\theta_{s}$. When $\rho>-\theta_{s}$, claiming sick-pay is more attractive than working undertime. This may lead to shirking behavior. On the other hand, $\rho<-\theta_{s}$ may lead to presenteeism, where sick employees come to work to collect undertime payment, see Chatterji and Tilley (2002).
} 
$h=\bar{h}$. This virtual premium is implicitly defined by $f(z, \bar{\theta})=1$. As a consequence, $\bar{\theta}$ is increasing in $z .{ }^{15}$ The prevailing actual premium $\theta$ can be found comparing the virtual premium $\bar{\theta}(z)$ with the short-time and overtime premium $\theta_{s}$ and $\theta_{o}$. This leads to the following proposition:

Proposition 5 Allowing for the possibility of short-time and corner solutions in the models under certainty, the relevant premium $\theta$ is determined as

$$
\theta= \begin{cases}\theta_{s} & \text { for } \bar{\theta}(z) \leq \theta_{s} \\ \bar{\theta}(z) & \text { for } \theta_{s}<\bar{\theta}(z)<\theta_{o} \\ \theta_{o} & \text { for } \theta_{o} \leq \bar{\theta}(z)\end{cases}
$$

This allows us to identify three cases:

- Structural overtime. For high values of $\bar{\theta}(z)$ - and thus high values of $z$ - permanent overtime will prevail. Intuitively, the marginal costs of the intensive margin - hours is relatively low compared to the marginal cost of the extensive margin - the number of employees. This was the case considered in Section 1.

- Normal hours. For intermediate levels of $\bar{\theta}(z)$ it is optimal to let the workweek correspond to the standard workweek $\bar{h}$.

- Structural short-time. Finally, there is even a range where structural short-time may prevail, but in view of the available evidence, this does not seem to be the most relevant option. ${ }^{16}$

\section{$5 \quad$ Uncertainty and short-time}

Incorporating the kinked compensation schedule (14) in the models with uncertainty, introduces various regimes in the model. There is a positive probability $\Phi_{s}$ that short-time occurs and hours fall below normal hours $\bar{h}$. Moreover, in the profit maximizing model there will be a probability $\bar{\Phi}$ that the corner solution at normal hours applies. The firm can influence the probabilities of these regimes to occur. For example, reducing the employment level $n$, the firm reduces the likelihood of the short-time regime, but at the cost of more overtime being worked. The firm should balance these issues.

\subsection{Cost minimization}

First consider the cost minimization model. Contrary to the certainty model, there is no corner solution. The reason is simple, ex post hours should always satisfy the constrained demand equation (7), and with continuous distributions of attendance $a$ and demand $q$, the mass of the corner solution $h=\bar{h}$ is zero. So there are just two regimes in the cost minimization model: shorttime and overtime. This makes the expected cost minimization problem analytically somewhat complex. It is solved in Appendix B. Although no closed form solution can be given, a succinct and useful expression for employment is

$$
n_{u}^{c}=E\left(q^{1 / \alpha \gamma}\right)^{\gamma} E\left(a^{-(1-\tau \gamma) / \tau \gamma}\right)^{\gamma} E(a)^{-\gamma} \bar{h}^{-\gamma} f\left(z+\Delta^{c}, \theta^{c}\right)^{-\gamma}
$$

where the virtual premium $\theta^{c} \in\left(\theta_{s}, \theta_{o}\right)$ is a weighted average of the overtime and short-time premiums $\theta_{o}$ and $\theta_{s}$ and $\Delta^{c}>0$. Exact definitions of these parameters are given in Appendix $\mathrm{B}$, but both depend on employment $n_{u}^{c}$. Hence, equation (16) only provides an implicit solution to employment.

\footnotetext{
${ }^{15}$ More specifically, the virtual premium is given as $\bar{\theta}(z)=\gamma z-(1-\gamma)$.

${ }^{16}$ For $\theta_{s}=0$ this can perhaps be interpreted as the part-time solution, as in Ortega (2003).
} 
The solution for expected hours can also be expressed in terms of these parameters, yielding

$$
E\left(h^{c}\right)=\delta_{h}^{c} f\left(z+\Delta^{c}, \theta^{c}\right) \bar{h} .
$$

Both equations closely resemble the solution for employment (8) and expected hours (9) found in the earlier cost minimization model with uncertainty of Section 2.1. The possible occurrence of the short-time regime generates two important differences:

- First the use of the premium rate $\theta^{c}$ instead of either $\theta_{o}$ or $\theta_{s}$. The reason is simple: whereas for high absenteeism and high demand attending employees will work overtime, they may work short-time for low absenteeism or low demand. Therefore, sometimes the overtime premium $\theta_{o}$ prevails, but in other cases the short-time premium $\theta_{s}$. The average premium $\theta^{c}$ paid is thus lower than the overtime premium $\theta_{o}$, but higher than the shorttime premium $\theta_{s}$. Accordingly, hours are substituted for employees and expected hours increase, but employment falls.

- The second difference is catched by the term $\Delta^{c}>0$. In the compensation schedule (13) the premium $\theta$ not only increases the marginal costs of hours, but also reduces the fixed costs of attending employees by $-\theta w \bar{h}$. In the stochastic case with the kinked compensation schedule (14), the average premium is $\theta^{c}$, but due to the kink the reduction in fixed costs of attending employees is less than $-\theta^{c} w \bar{h}$. The reason is that the average premium $\theta^{c}$ also reflects the convex relation between hours worked and absenteeism or demand, whereas for the reduction in fixed costs of attending employees it mainly matters whether overtime is worked or not. This difference is captured by the term $\Delta^{c}>0 .{ }^{17}$ As a consequence, the costs of the extensive margin increase, leading to another substitution effect towards more hours worked and less employees.

Comparing equations (17) and (9), the impact of these two substitution effects on expected hours is given by the ratio

$$
\lambda_{h}^{c} \equiv \frac{f\left(z+\Delta^{c}, \theta^{c}\right)}{f(z, \theta)},
$$

where the relevant premium $\theta$ of the denominator is defined by Proposition 5. For employment the substitution effect is $\lambda_{n}^{c} \equiv \lambda_{h}^{c^{-\gamma}}$. These $\lambda$-terms capture the impact of uncertainty through the variation in the premium rates. Their size is ambiguous and depends on the point of departure: with structural overtime under certainty, $\lambda_{h}^{c}>1$, expected hours unambiguously increase and employment decreases through this mechanism; but the opposite would hold with structural short-time under certainty. The proposition summarizes.

Proposition 6 Allowing for the possibility of short-time in the cost minimization model under uncertainty, leads to a substitution effect between hours and employees. The sign and size of the effect depends on $\lambda_{h}^{c}$ :

- $\lambda_{h}^{c}>1$ in case of structural overtime under certainty and expected hours increase;

- $\lambda_{h}^{c} \gtreqless 1$ in case of normal hours under certainty;

- $\lambda_{h}^{c}<1$ in case of structural short-time under certainty and expected hours decrease.

\section{Proof. See Appendix B.}

\footnotetext{
${ }^{17}$ In Appendix B the reduction in fixed costs of attending employees is shown to be $-\tilde{\theta}^{c} w h^{n}$, with $\theta_{s}<\tilde{\theta}^{c}<$ $\theta^{c}<\theta_{o}$. The parameter $\Delta^{c}=\theta^{c}-\tilde{\theta}^{c}>0$ measures the difference.
} 


\subsection{Profit maximization: a spike at normal hours}

In the profit maximizing model, optimal hours are given by equation (10). Whether overtime or short-time prevails does depend on the price level $p$. Let $\bar{p}(\theta)$ denote the price level where actual and normal hours coincide, so

$$
\bar{p}(\theta)=\frac{(1+\theta) w a^{-(\alpha-\tau) / \tau} \bar{h}^{1-\alpha \gamma} n^{1-\alpha}}{\alpha \gamma},
$$

and $\bar{p}(\theta)$ is increasing in the prevailing premium $\theta$. As a consequence, $\bar{p}\left(\theta_{o}\right)>\bar{p}\left(\theta_{s}\right)$ and actual hours will be equal to normal hours as long as the price $p$ is within this interval. The probability of this state to occur is

$$
\bar{\Phi}^{p}=\operatorname{Pr}[h=\bar{h}]=\int_{0}^{1} \int_{\bar{p}\left(\theta_{s}\right)}^{\bar{p}\left(\theta_{o}\right)} d F_{p}(p) d F_{a}(a) .
$$

The profit maximizing model thus predicts a spike at normal hours, as in Ortega (2003). This is a very attractive feature of the model, corresponding to the stylized facts of the hours distribution.

There is again no closed form solution, but using virtual overtime premiums, the solution can be written as

$$
n_{u}^{p}=\left(\frac{\alpha \gamma E\left(p^{\frac{1}{1-\alpha \gamma}}\right)^{1-\alpha \gamma} E\left(a^{\frac{\alpha(1-\tau \gamma)}{\tau(1-\alpha \gamma)}}\right)^{1-\alpha \gamma}}{\left(1+\theta_{n}^{p}\right) w E(a)^{1-\alpha \gamma} f\left(z+\Delta_{n}^{p}, \theta_{n}^{p}\right)^{1-\alpha \gamma} \bar{h}^{1-\alpha \gamma}}\right)^{1 /(1-\alpha)}
$$

with expected hours

$$
E(h)=\delta_{h}^{p} f\left(z+\Delta^{p}, \theta^{p}\right) \bar{h} .
$$

As before, the virtual premiums $\theta_{n}^{p}>\theta^{p}$ are weighted averages of the overtime and shorttime premiums $\theta_{o}$ and $\theta_{s}$ and $\Delta_{n}^{p}>\Delta^{p}>0$. Exact definitions of these parameters are given in Appendix C, but they depend on employment $n_{u}^{p}$. Hence, equation (18) only provides an implicit solution to employment. Nevertheless, these equations are rather similar to the solution for employment (11) and expected hours (12) found in the earlier profit maximization model with uncertainty, but without short-time or corner solutions. Again the difference is the use of the virtual premiums, leading to a substitution effect between hours and employment, and a scale effect for employment.

For expected hours, the size of the substitution effect is given by

$$
\lambda_{h}^{p} \equiv \frac{f\left(z+\Delta^{p}, \theta^{p}\right)}{f(z, \theta)} .
$$

For employment, there is an additional scale effect of the virtual premium rate, working in the opposite direction of the substitution effect. The total impact is denoted $\lambda_{n}^{p}$, which is inversely related to $\lambda_{h}^{p}$, see Appendix C. To summarize

Proposition 7 Allowing for the possibility of short-time and corner solutions in the profit maximization model under uncertainty, leads to a substitution effect between hours and employment and a scale effect for employment. The sign and size of the substitution effect depends on $\lambda_{h}^{p}$, whereas the total effect on employment is determined by $\lambda_{n}^{p}$.

Proof. See Appendix C.

Contrary to the cost minimization model, it is no longer possible to determine the sign of the effects analytically. So we have to use numerical simulations. 


\section{$5.3 \quad$ Numerical example}

The parameters of the production function and the distributions of absenteeism and demand are the same as used in the numerical Section 2.3, although we concentrate on the cases with low variances of demand and absenteeism. Furthermore, we need some parameters of the cost structure. $^{18}$ In line with the results of Bell and Hart (2003), the overtime premium is set as $\theta_{o}=0.3$. This is lower than the legislated 0.5 in the US, but seems fairly representative for European countries. The short-time premium is set at $\theta_{s}=0$, so it is not costly for firms to reduce hours below normal hours.

Finally, we need to determine $z$, the fixed labor costs as a percentage of normal wage costs. This variable is calibrated to obtain meaningful levels of relative overtime hours in (3). Setting $f\left(z, \theta_{o}\right)=1.05$, implies $z=0.641$. So, quasi-fixed labor costs are non-negligible, as documented in Hart (1984). ${ }^{19}$ To allow for the possibility of normal hours in the certainty case, equation (15) provides a range of values for $z$ : for $z \in[0.25,0,625]$ the certainty model would predict a corner solution at normal hours. The value of $z=0.45$ used by Chen and Funke (2004) is used for comparison.

Table 3 provides the results. Column (1) gives the benchmark simulations for $z=0.641$, where structural overtime hours would thus be $5 \%$ of normal hours in the certainty case. Allowing for short-time in the cost minimization model, the stochastic fluctuations in demand and attendance reduce the average premium from 0.3 to $0.26\left(\theta^{c}\right)$. At the same time this raises fixed labor costs $z$ by 1.5 percentage points $\left(\Delta^{c}\right)$. Jointly, these two effect lead to a substitution from employment to hours: expected hours increase by almost $20 \%\left(\lambda_{h}^{c}\right)$, whereas employment falls by $14 \%\left(\lambda_{h}^{c}\right)$. The probability that hours fall below normal hours is almost $18 \%\left(\Phi_{s}^{c}\right)$.

In the profit maximization model the direction of the effects is similar, but somewhat smaller in size. This is due to the positive scale effect on employment of the lower premium rate. The average premium rate is now $0.275\left(\theta^{p}\right)$, and the fixed cost increase by 0.5 percentage points $\left(\Delta^{p}\right)$. As a consequence, expected hours increase by almost $11 \%\left(\lambda_{h}^{p}\right)$ and employment falls by about $9 \%\left(\lambda_{n}^{p}\right)$. The probability of the short-time regime is very small $\left(\Phi_{s}^{p}\right)$, but $35 \%$ of the time the corner solution with hours equal to normal hours applies $\left(\bar{\Phi}^{p}\right)$. So the profit maximizing model can account for a significant spike of hours at normals hours.

The other columns of Table 3 investigate the sensitivity of the results for other parameter values. Column (2) eliminates teamwork, whereas column (3) considers the case of strong teamwork. No substantial differences are found. Columns (4) and (5) increase the variance of demand or absenteeism. Especially the standard deviation of demand increases the impact on expected hours. Column (6) considers the impact of a generous short-time payment system, where workers would still get their normal income working short-time. To reduce the likelihood of short-time, employment is further decreased. Hence expected hours increase much more in the cost minimization model. As the probability of short-time was almost non-existent in the profit maximizing model, nothing really changes there.

The two final columns consider changes in the relative fixed costs $z$. In both cases, the optimal solution under certainty would be the corner solution at normal hours. The latter value of $z=0.25$, is the lowest value for which the certainty solution would correspond to the corner solution. In both cases the premium $\theta^{c}$ is reduced (much) more, and fixed costs $\Delta^{c}$ increase more, than in the benchmark column (1). Nevertheless, the impact on expected hours and employment, as measured by $\lambda_{h}^{c}$ and $\lambda_{n}^{c}$, respectively, is much lower. This is due to the

\footnotetext{
${ }^{18} \mathrm{~A}$ number of parameters is only needed to determine the absolute value of employment, which will not be reported. Their choice is innocuous. Hourly wages $w$ are normalized to one and normal hours are set at $\bar{h}=40$. The expected demand $E(q)$ and expected price $E(p)$ are normalized to generate an employment level under certainty of $n_{c}^{c}=n_{c}^{p}=100$.

${ }^{19}$ However, the value of $z$ depends strongly on the parameters $\gamma$ and $\theta_{o}$. To illustrate, $z=0.451$ for $\gamma=0.9$, and $z=0.894$ for $\theta_{o}=0.5$. One should thus be careful interpreting the absolute value of $z$. Alternatively, good estimates of $z$, together with information about the overtime premium, could help to determine $\gamma$, the elasticity of hours in the production function.
} 
Table 3: Uncertainty and short-time

\begin{tabular}{ccccccccc}
\hline & Basic & \multicolumn{2}{c}{ Teamwork } & \multicolumn{2}{c}{ Variance } & Premium & \multicolumn{2}{c}{ Corner solution } \\
& & $\tau=1$ & $\tau=0.6$ & $\sigma_{q}=0.2$ & $\sigma_{a}^{2}=$ & $\theta_{s}=-1$ & $z=0.45$ & $z=0.25$ \\
& & & $\sigma_{p}=0.2$ & 0.015 & & & \\
\multicolumn{2}{c}{$(1)$} & $(2)$ & $(3)$ & $(4)$ & $(5)$ & $(6)$ & $(7)$ & $(8)$ \\
\hline \multicolumn{2}{c}{ Cost minimization } & & & & & & \\
$\theta^{c}$ & 0.260 & 0.262 & 0.256 & 0.250 & 0.258 & 0.239 & 0.172 & 0.056 \\
$\Delta^{c}$ & 0.015 & 0.014 & 0.018 & 0.034 & 0.017 & 0.031 & 0.028 & 0.021 \\
$\lambda_{h}^{c}$ & 1.198 & 1.187 & 1.222 & 1.297 & 1.210 & 1.333 & 1.045 & 0.811 \\
$\lambda_{n}^{c}$ & 0.865 & 0.872 & 0.852 & 0.812 & 0.858 & 0.795 & 0.965 & 1.183 \\
$\Phi_{s}^{c}$ & 0.176 & 0.167 & 0.198 & 0.272 & 0.186 & 0.068 & 0.502 & 0.857 \\
\hline Profit maximization & & & & & & \\
$\theta^{p}$ & 0.275 & 0.276 & 0.271 & 0.252 & 0.276 & 0.275 & 0.164 & 0.031 \\
$\Delta^{p}$ & 0.005 & 0.007 & 0.002 & 0.002 & 0.006 & 0.005 & 0.007 & 0.006 \\
$\lambda_{h}^{p}$ & 1.109 & 1.113 & 1.113 & 1.243 & 1.109 & 1.109 & 1.005 & 0.875 \\
$\lambda_{n}^{p}$ & 0.914 & 0.911 & 0.913 & 0.816 & 0.914 & 0.914 & 0.972 & 1.100 \\
$\Phi_{s}^{p}$ & 0.001 & 0.002 & 0.003 & 0.067 & 0.001 & 0.000 & 0.073 & 0.649 \\
$\bar{\Phi}^{p}$ & 0.351 & 0.354 & 0.362 & 0.357 & 0.349 & 0.352 & 0.799 & 0.350 \\
\hline
\end{tabular}

lower fixed costs $z$ in $f\left(z+\Delta^{c}, \theta^{c}\right)$. In line with Proposition 6, expected hours increase for intermediate values of $z$, column (7), but decrease for low values of $z$, column (8). In the latter case the probability of the short-time regime becomes unrealistically high, even in the profit maximization model. However, for the intermediate level of $z=0.45$, the profit maximization model mainly predicts a larger spike at normal hours. Expected hours increase, but only to a limited amount.

To obtain the total impact of uncertainty on hours and employment, the direct impact of convexity and concavity in expectation formation as measured by the $\delta$ 's of Tables 1 and 2 should be included. Table 4 provides the total effect and its decomposition. The table considers the benchmark case (1), as well as the corner solution (7) of Table 3. One the one hand, the $\delta$-rows identify the non-linearity effects of uncertainty at fixed overtime premium rate, whereas the $\lambda$-rows give the indirect effect of reduced average premium rates when allowing for shorttime and corner solutions. The total effect is the product of the two. One the other hand, the columns labeled demand and absenteeism, decompose the effects of the total columns (1) or (4) into separate effects of stochastic demand and stochastic absenteeism, respectively. Absent interaction effects, the total column would be the product of these underlying effects.

Employment decreases in column (1), as the negative premium effects $(\lambda)$ dominate the positive non-linearity effect $(\delta)$. For expected hours both effects work in the same direction, but the bulk of the effect occurs through the premium effect. These observations hold for both the cost minimization model and the profit maximizing model, but the effects are smaller in the latter case. Looking at columns (2) and (3), the bulk of the total and premium effects comes from demand uncertainty. This is not true for the non-linearity effects, however. For employment this effect is similar for stochastic demand and stochastic absenteeism, but for expected hours the non-linearity effect is solely due to stochastic absenteeism. So as is most clear from the profit maximizing model, the impact of stochastic demand and stochastic absenteeism on expected hours mainly operates through different channels: demand uncertainty operates through the premium effect, whereas stochastic absenteeism operates through the non-linearity effect.

Looking at column (4) - with a corner solution under certainty - the premium effects $(\lambda)$ are much smaller than in column (1). The effects of non-linearity $(\delta)$ are exactly similar to column 
Table 4: Decomposition stochastic effects

\begin{tabular}{llcccccc}
\hline & \multicolumn{3}{c}{$z=0.641$} \\
\cline { 3 - 7 } & & $\begin{array}{c}\text { Total } \\
(1)\end{array}$ & $\begin{array}{c}\text { Demand } \\
(2)^{a}\end{array}$ & $\begin{array}{c}\text { Absenteeism } \\
(3)^{b}\end{array}$ & $\begin{array}{c}\text { Total } \\
(4)\end{array}$ & $\begin{array}{c}\text { Demand } \\
(5)^{a}\end{array}$ & $\begin{array}{c}\text { Absenteeism } \\
(6)^{b}\end{array}$ \\
\hline Employment & $n_{u}^{c} / n_{c}^{c}$ & 0.875 & 0.891 & 0.974 & 0.976 & 0.991 & 0.945 \\
& $\delta_{n}^{c}$ & 1.012 & 1.006 & 1.006 & 1.012 & 1.006 & 1.006 \\
Hours & $\lambda_{n}^{c}$ & 0.865 & 0.886 & 0.968 & 0.965 & 0.986 & 0.939 \\
& $E\left(h^{c}\right) / h^{*}$ & 1.245 & 1.164 & 1.083 & 1.086 & 1.019 & 1.124 \\
& $\delta_{h}^{c}$ & 1.039 & 1.000 & 1.039 & 1.039 & 1.000 & 1.039 \\
& $\lambda_{h}^{c}$ & 1.198 & 1.164 & 1.042 & 1.045 & 1.018 & 1.082 \\
\hline Employment & $n_{u}^{p} / n_{c}^{p}$ & 0.932 & 0.934 & 0.998 & 0.990 & 0.993 & 0.998 \\
& $\delta_{n}^{p}$ & 1.019 & 1.021 & 0.998 & 1.019 & 1.021 & 0.998 \\
& $\lambda_{n}^{p}$ & 0.914 & 0.915 & 1.000 & 0.972 & 0.972 & 1.000 \\
& $E\left(h^{p}\right) / h^{*}$ & 1.114 & 1.109 & 1.004 & 1.010 & 1.008 & 1.000 \\
& $\delta_{h}^{p}$ & 1.004 & 1.000 & 1.004 & 1.004 & 1.000 & 1.004 \\
& $\lambda_{h}^{p}$ & 1.109 & 1.109 & 1.000 & 1.005 & 1.008 & 0.996 \\
\hline$a$
\end{tabular}

${ }^{a}$ Simulated with $\sigma_{a}^{2}=0.0001$.

${ }^{b}$ Simulated with $\sigma_{q}=\sigma_{p}=0.001$.

(1), as this effect is independent of the original situation. Roughly speaking, the premium and non-linearity effects of column (4) contribute in the same amount to the total effect on expected hours, but the premium effects still dominate for employment. For the profit maximization model, the decomposition into the sources of uncertainty in columns (5) and (6) confirms the findings of the model with higher fixed costs: the total effect is roughly speaking the product of the separate effects; and demand dominates for employment.

In the cost minimization model the impact of only stochastic absenteeism is much larger than the combined effect of stochastic demand and absenteeism, however. This is due to the right-skewness of the attendance distribution. Without any uncertainty, hours worked would be equal to normal hours. Given the weak teamwork effect $(\tau>\alpha)$, see Proposition 3, the non-linearity effect $(\delta)$ slightly decreases employment with stochastic attendance. This suggests that overtime becomes relevant. But with a median of 0.995 and a mean of 0.95 , the density of attendance is right-skewed. So most of the time high attendance will reduce hours into the shorttime regime to satisfy the demand constraint (7). As a consequence, the effective premium rate falls, which in turn induces substitution towards longer hours and less employment. Although this somewhat further reduces the likelihood of short-time, expected hours strongly increase. This effect is much less pronounced in the profit maximization model of column (6), as the firm has a range of attendance rates for which it will remain producing at the corner solution. In column (3) the effect is not so strong because overtime is worked in the certainty case. Hence short-time is less likely to occur, reducing the large premium effects of column (6). As demand is symmetrically distributed around its mean, the premium effects in column (5) are weaker than in column (6). The symmetric distribution of demand also reduces the impact of absenteeism in the joint column (4). 


\section{Conclusion}

Volatility in demand and attendance tend to increase average hours per worker. More specifically, stochastic absenteeism and stochastic demand affect expected hours demand in basically two different ways:

- At a fixed overtime premium rate, random fluctuations in absence tends to increase average hours above the certainty hours level, whereas random fluctuations in demand do not change expected hours. Moreover, the random variations in demand increase employment above the certainty level, whereas random variations in absence have an ambiguous impact on employment.

- Moreover, the random fluctuations in absenteeism and demand change the effective premium rate, as low absenteeism or low demand may force employees to work normal time or short-time. Compared to the certainty case with structural overtime, expected hours will unambiguously increase and the number of employees will decrease.

The relative size of these effects depends on the type of uncertainty. Moreover, they occur both in cost minimizing and profit maximizing models. In the latter model the reduction in effective premium rates is lower, due to the added scale effect of the lower costs. Still, the reduction in effective premium rates appears to dominate the employment effects. The main advantage of the profit maximizing model is that it unambiguously allows for the widely observed spike at normal hours.

In any case, the results indicate that observed overtime may well result from the random nature of absenteeism and demand, instead of structural cost minimizing factors. Therefore, one should be very careful with inference based on models with structural overtime. The corner solution at normal hours may have more relevance than the observed average overtime hours seems to suggest.

The main empirical hypothesis implied by the paper is that the volatility of absenteeism and demand will increase overtime hours. It will not be easy to test, however, as information about volatility of absenteeism or demand is much harder to get than information about their levels.

Besides empirical testing, future research should also extend the theoretical analysis. An important distinction is the choice between overtime incidence and overtime hours. Moreover, absenteeism should be endogenized. Both aspects underline the importance of labor supply factors, and stress the need for analyzing the link between overtime and absenteeism in a partial equilibrium framework.

\section{References}

[1] Allen S. G. (1983), How Much Does Absenteeism Cost?, Journal of Human Resources, vol. 18(3), pp. 379-93.

[2] Ashworth J., A. McGlone and D. Ulph (1977), Uncertainty, Overtime and the Demand for Labour, Zeitschrift fur Nationalokonomie, vol. 37(3-4), pp. 323-336.

[3] Audas R. and J. Goddard (2001), Absenteeism, seasonality, and the business cycle, Journal of Economics and Business, vol. 53, pp. 405-419.

[4] Bell D. N. F. and R. A. Hart (2003), Wages, Hours, and Overtime Premia: Evidence from the British Labor Market, Industrial and Labor Relations Review, vol. 56 (3), pp. 470-480.

[5] Bell D.N.F., R.A. Hart, O. Hübler and W. Schwerdt (2000), Paid and Unpaid Overtime Working in Germany and the UK, Discussion Paper 133, IZA, Bonn. 
[6] Chatterji M. and C.J. Tilley (2002), Sickness, absenteeism, presenteeism, and sick pay, Oxford Economic Papers, vol. 54 (4), pp. 669-687.

[7] Chen Y.-F. and M. Funke (2004), Working Time and Employment Under Uncertainty, Studies in Nonlinear Dynamics \& Econometrics, vol. 8(3), article 5, http://www.bepress.com/snde/vol8/iss3/art5.

[8] Coles M.G. and J.G. Treble (1996), Calculating the Price of Worker Reliability, Labour Economics, vol. 3 (2), pp. 169-188.

[9] DeLeire T., J. Bhattacharva and T. MaCurdy (2002), Comparing Measures of Overtime Across BLS Surveys, Industrial Review, vol. 41 (2), pp. 362-369.

[10] Ehrenberg R.G. (1970), Absenteeism and the Overtime Decision, American Economic Review, vol. 60 (3), pp. 352-357.

[11] Friesen J. (2002), overtime pay regulation and weekly hours of worl in Canada, Labour Economics, vol. 8 (6), pp. 691-720.

[12] de Grip A., J. van Loo, and I. Sieben (2003), Arbeidsmarktmonitor Metalektro 2002, ROA report ROA-R-2003/8, Maastricht, in Dutch.

[13] Hamermesh D.S. (1993), Labor Demand, Princeton University Press, Princeton.

[14] Hart R.A. (1984), The Economics of Non-Wage Labour Costs, Allen \& Unwin, London.

[15] Hart R.A. (2004), The Economics of Overtime Working, Cambridge University Press, Cambridge.

[16] Kalwij A.S. and M. Gregory (2003), Paid overtime hours worked by British men from 1975 to 1999, Working paper, Oxford University.

[17] OECD (1998), Working Hours: latest trends and policy initiatives, pp. 153-188 in OECD (ed.) (1998), Employment Outlook, OECD, Paris.

[18] Ortega J. (2003), Working-time regulation, firm heterogeneity, and efficiency, CEPR discussion paper 3736, London.

[19] de Regt E.R. (2005a), Returns to hours, mimeo, University Maastricht.

[20] de Regt E.R. (2005b), The demand of overtime: hours and incidence, mimeo, University Maastricht.

[21] Trejo S.J. (1993), Overtime Pay, Overtime Hours, and Labor Unions, Journal of Labor Economics, vol. 11 (2), pp. 253-278.

[22] Trejo S. J. (2003), Does the Statutory Overtime Premium Discourage Long Workweeks?, Industrial and Labor Relations Review, vol. 56 (3), pp. 530-551.

[23] Van Audenrode M. A. (1994), Short-Time Compensation: Job Security, and Employment Contracts: Evidence from Selected OECD Countries, Journal of Political Economy, vol. 102 (1), pp, 76-102.

[24] Yaniv G. (1986), Absenteeism, Overtime, and the Compressed Workweek, Journal of Behavioral Economics, vol. 15 (1/2), pp. 211-219. 


\section{Appendix A}

\section{A.1 Proof of proposition 1}

Consider $\tilde{\delta}_{n}^{c} \equiv \delta_{n}^{c^{1 / \gamma}}=\frac{E\left(q^{1 / \alpha \gamma}\right)}{E(q)^{1 / \alpha \gamma}} \frac{E\left(a^{-(1-\tau \gamma) / \tau \gamma}\right)}{E(a)^{-(1-\tau \gamma) / \tau \gamma}}$. Both $q^{1 / \alpha \gamma}$ and $a^{-(1-\tau \gamma) / \tau \gamma}$ are convex functions, therefore applying twice Jensen's inequality implies $\tilde{\delta}_{n}^{c}>1$. Hence $\delta_{n}^{c}=\tilde{\delta}_{n}^{c^{\gamma}}>1$.

\section{A.2 Proof of proposition 2}

Consider $\delta_{h}^{c} \equiv \frac{E(a) E\left(a^{-1 / \tau \gamma}\right)}{E\left(a^{-(1-\tau \gamma) / \tau \gamma}\right)}$. First, notice that $x^{1-\tau \gamma}$ is a concave function. Therefore, using Jensen's inequality, $E\left(a^{-(1-\tau \gamma) / \tau \gamma}\right)<E\left(a^{-1 / \tau \gamma}\right)^{1-\tau \gamma}$ and $\delta_{h}^{c}>E(a) E\left(a^{-1 / \tau \gamma}\right)^{\tau \gamma}$. Moreover, $a^{-1 / \tau \gamma}$ is a convex function and Jensen's inequality implies $E\left(a^{-1 / \tau \gamma}\right)^{\tau \gamma}>E(a)^{-1}$. Hence, $\delta_{h}^{c}>1$.

Independence of expected hours of demand uncertainty follows as $\delta_{h}^{c}$ has no terms involving the quantity $q$.

\section{A.3 Proof of proposition 3}

Define $\tilde{\delta}_{n}^{p} \equiv \delta_{n}^{p^{1-\alpha}}=\frac{E\left(p^{\frac{1}{1-\alpha \gamma}}\right)^{1-\alpha \gamma}}{E(p)} \frac{E\left(a^{\frac{\alpha(1-\tau \gamma)}{\tau(1-\alpha \gamma)}}\right)^{1-\alpha \gamma}}{E(a)^{\alpha(1-\tau \gamma) / \tau}}$. Consider first the impact of the price $p$ on $\tilde{\delta}_{n}^{p}$. As $p^{1 /(1-\alpha \gamma)}$ is a convex function, Jensen's inequality implies $E\left(p^{1 /(1-\alpha \gamma)}\right)>E(p)^{1 /(1-\alpha \gamma)}$. This works in the direction of $\tilde{\delta}_{n}^{p}>1$ and thus $\delta_{n}^{p}>1$.

For attendance $a$, first notice that $\frac{\alpha(1-\tau \gamma)}{\tau(1-\alpha \gamma)} \gtreqless 1$ for $\alpha \gtreqless \tau$. So for $\alpha>\tau$ the function $a^{\frac{\alpha(1-\tau \gamma)}{\tau(1-\alpha \gamma)}}$ is convex and Jensen's inequality works in the direction of $\tilde{\delta}_{n}^{p}>1$. However, for $\alpha<\tau$ the function $a^{\frac{\alpha(1-\tau \gamma)}{\tau(1-\alpha \gamma)}}$ is concave and Jensen's inequality works in the opposite direction of $\tilde{\delta}_{n}^{p}<1$.

\section{A.4 Proof of proposition 4}

Consider $\delta_{h}^{p} \equiv \frac{E(a) E\left(a^{\frac{\alpha-\tau}{\tau(1-\alpha \gamma)}}\right)}{E\left(a^{\frac{\alpha(1-\tau \gamma)}{\tau(1-\alpha \gamma)}}\right)}$. For $\alpha=\tau$, the expression implies $\delta_{h}^{p}=1$. For $\alpha \neq \tau$, define $\mu \equiv \frac{\alpha-\tau}{\tau(1-\alpha \gamma)}$, so $\delta_{h}^{p}=\frac{E(a) E\left(a^{\mu}\right)}{E\left(a^{1+\mu}\right)}$. Let $\alpha<\tau$, then $\mu \in(-1,0)$. The function $a^{\mu}$ is convex, whereas $a^{1+\mu}$ is concave. Applying Jensen's inequalities twice implies $\delta_{h}^{p}>1$.

Second, let $\alpha>\tau$, implying $\mu>0$. Notice that $\delta_{h}^{p}$ can be written as $\delta_{h}^{p}=\frac{E\left(a^{\frac{1+\mu}{1+\mu}}\right) E\left(a^{(1+\mu) \frac{\mu}{1+\mu}}\right)}{E\left(a^{1+\mu}\right)}$. As $x^{1 /(1+\mu)}$ and $x^{\mu /(1+\mu)}$ in the numerator are both concave functions, Jensen's inequality implies $\delta_{h}^{p}<\frac{E\left(a^{1+\mu}\right)^{1 /(1+\mu)} E\left(a^{(1+\mu)}\right)^{\mu /(1+\mu)}}{E\left(a^{1+\mu}\right)}=1$.

Independence of expected hours of demand or price shocks follows as $\delta_{h}^{p}$ has no terms involving the price $p$. 


\section{Appendix B Expected cost minimization}

\section{B.1 Expected cost minimization}

Using the compensation schedule $o(h)$, expected costs are given by

$$
E(C)=w[z E(a) \bar{h}+E(a o(h))] n .
$$

Although $o(h)$ is non-differentiable at $h=\bar{h}$, this problem is solved using the expectations operator, as the corner solution has mass zero in the cost minimizing model. Using (7), we have $\frac{\partial h}{\partial n}=-\frac{1}{\gamma} \frac{h}{n}$. So the first-order condition for cost minimization is

$$
0=\frac{d E(C)}{d n}=w[z E(a) \bar{h}+E(a o(h))]-\frac{1}{\gamma} w E\left(a o^{\prime}(h) h\right) .
$$

Let $F_{a}(a)$ and $F_{q}(q)$ denote the cumulative distribution functions of attendance $a$ and demand $q$, respectively. Moreover, let $\bar{q} \equiv a^{\alpha / \tau} n^{\alpha} \bar{h}^{\alpha \gamma}$ be the demand level where exactly normal hours are worked. Then the expected value in the last term can be rewritten as

$$
\begin{aligned}
E\left(a o^{\prime}(h) h\right) & =\left(1+\theta_{o}\right) E(a h)-\left(\theta_{o}-\theta_{s}\right) \int_{0}^{1} \int_{0}^{\bar{q}} a h d F_{q}(q) d F_{a}(a) \\
& =\left(1+\theta^{c}\right) E(a h),
\end{aligned}
$$

with

$$
\theta^{c} \equiv\left(1-\omega^{c}(n)\right) \theta_{o}+\omega^{c}(n) \theta_{s}
$$

and

$$
\omega^{c}(n) \equiv \int_{0}^{1} \int_{0}^{\bar{q}} \frac{a h}{E(a h)} d F_{q}(q) d F_{a}(a) .
$$

As $\bar{q}$ is increasing in $n$, the weight $\omega^{c}(n)$ is increasing in $n$, with $\omega^{c}(0)=0$ and $\lim _{n \rightarrow \infty} \omega^{c}(n)=1$. So $\theta^{c} \in\left(\theta_{s}, \theta_{o}\right)$.

The term in the right-hand side of equation (B.1) involving the compensation schedule $o(h)$ can be expressed as

$$
\begin{aligned}
E(a o(h)) & =\left(1+\theta_{o}\right) E(a h)-\theta_{o} E(a) \bar{h}+\left(\theta_{o}-\theta_{s}\right) \int_{0}^{1} \int_{0}^{\bar{q}} a(\bar{h}-h) d F_{q}(q) d F_{a}(a) \\
& =\left(1+\theta^{c}\right) E(a h)-\tilde{\theta}^{c} E(a) \bar{h},
\end{aligned}
$$

with

$$
\tilde{\theta}^{c} \equiv\left(1-\tilde{\omega}^{c}(n)\right) \theta_{o}+\tilde{\omega}^{c}(n) \theta_{s}
$$

and

$$
\tilde{\omega}^{c}(n) \equiv \int_{0}^{1} \int_{0}^{\bar{q}} \frac{a}{E(a)} d F_{q}(q) d F_{a}(a) .
$$

The weight $\tilde{\omega}^{c}(n)$ is increasing in $n$, with $\tilde{\omega}^{c}(0)=0$ and $\lim _{n \rightarrow \infty} \tilde{\omega}^{c}(n)=1$. So $\tilde{\theta}^{c} \in\left(\theta_{s}, \theta_{o}\right)$.

To compare both premium rates, define

$$
\Delta^{c} \equiv \theta^{c}-\tilde{\theta}^{c}=\left(\theta_{o}-\theta_{s}\right) d(n),
$$


with

$$
d(n) \equiv \tilde{\omega}^{c}(n)-\omega^{c}(n)=\int_{0}^{1} \int_{0}^{\bar{q}}\left(\frac{a}{E(a)}-\frac{a h}{E(a h)}\right) d F_{q}(q) d F_{a}(a) .
$$

Using equation (7), notice that $\frac{a h}{E(a h)}=\frac{q^{1 / \alpha \gamma} a^{-(1-\tau \gamma) / \tau \gamma}}{E\left(q^{1 / \alpha \gamma} a^{-(1-\tau \gamma) / \tau \gamma}\right)}$. Using the definition of $\bar{q}$, differentiating $d(n)$ yields

$$
d^{\prime}(n)=\alpha n^{\alpha-1} \bar{h}^{\alpha \gamma} \int_{0}^{1}\left(\frac{a^{(\alpha+\tau) / \tau}}{E(a)}-\frac{a n^{1 / \gamma} \bar{h}}{E\left(q^{1 / \alpha \gamma} a^{-(1-\tau \gamma) / \tau \gamma}\right)}\right) f_{q}(\bar{q}) d F_{a}(a) .
$$

where $f_{q}(q)$ is the density function of demand $q$. It can be checked that $d^{\prime}(n)$ is positive for small $n$ and negative for large $n$. As $d(0)=\lim _{n \rightarrow \infty} d(n)=0$, this implies $d(n)>0$ for $n>0$. Hence $\Delta^{c}>0$, or $\theta^{c}>\tilde{\theta}^{c}$, for $\theta_{o}>\theta_{s}$.

Using the premia $\theta^{c}$ and $\tilde{\theta}^{c}$, the first-order condition (B.1) can be rearranged as

$$
\gamma\left[\left(z-\tilde{\theta}^{c}\right) E(a) \bar{h}+\left(1+\theta^{c}\right) E(a h)=\left(1+\theta^{c}\right) E(a h),\right.
$$

or

$$
E(a h)=\frac{\gamma}{1-\gamma} \frac{z-\tilde{\theta}^{c}}{1+\theta^{c}} E(a) \bar{h}=f\left(z+\theta^{c}-\tilde{\theta}^{c}, \theta^{c}\right) E(a) \bar{h}
$$

Hence

$$
E(a h)=f\left(z+\Delta^{c}, \theta^{c}\right) E(a) \bar{h} .
$$

Again using (7), notice that $E(a h)=E\left(q^{1 / \alpha \gamma} a^{-(1-\tau \gamma) / \tau \gamma} n^{-1 / \gamma}\right)$. Hence, as $q$ and $a$ independently distributed, the solution for employment is

$$
n_{u}^{c}=E\left(q^{1 / \alpha \gamma}\right)^{\gamma} E\left(a^{-(1-\tau \gamma) / \tau \gamma}\right)^{\gamma} E(a)^{-\gamma} \bar{h}^{-\gamma} f\left(z+\Delta^{c}, \theta^{c}\right)^{-\gamma} .
$$

For expected hours, notice that

$$
\frac{E(a) E(h)}{E(a h)}=\frac{E(a) E\left(q^{1 / \alpha \gamma} a^{-1 / \tau \gamma} n^{-1 / \gamma}\right)}{E\left(q^{1 / \alpha \gamma} a^{-(1-\tau \gamma) / \tau \gamma} n^{-1 / \gamma}\right)}=\frac{E(a) E\left(a^{-1 / \tau \gamma}\right)}{E\left(a^{-(1-\tau \gamma) / \tau \gamma}\right)}=\delta_{h}^{c} .
$$

So (B.2) implies

$$
E(h)=\delta_{h}^{c} f\left(z+\Delta^{c}, \theta^{c}\right) \bar{h} .
$$

\section{B.2 Proof of proposition 6 .}

For structural overtime, $\theta=\theta_{o}$ and $\lambda^{c}=\frac{f\left(z+\Delta^{c}, \theta^{c}\right)_{u}}{f\left(z, \theta_{o}\right)}$. As $\partial f / \partial z>0$ and $\partial f / \partial \theta<0$, and because $\Delta^{c}>0$ and $\theta^{c}<\theta_{o}$, we have $f\left(z, \theta_{o}\right)<f\left(z+\Delta^{c}, \theta^{c}\right)$. Hence $\lambda^{c}>1$.

For structural short-time, $\theta=\theta_{s}$ and $\lambda^{c}=\frac{f\left(z+\Delta^{c}, \theta^{c}\right)}{f\left(z, \theta_{s}\right)}$. Consider the difference

$$
\begin{aligned}
\Delta & =f\left(z, \theta_{s}\right)-f\left(z+\Delta^{c}, \theta^{c}\right)=\frac{\gamma}{1-\gamma}\left(\frac{z-\theta_{s}}{1+\theta_{s}}-\frac{z-\tilde{\theta}^{c}}{1+\theta^{c}}\right) \\
& =\frac{\gamma}{1-\gamma} \frac{\left(z-\theta_{s}\right)\left(\theta^{c}-\theta_{s}\right)+\left(\tilde{\theta}^{c}-\theta_{s}\right)\left(1+\theta_{s}\right)}{\left(1+\theta_{s}\right)\left(1+\theta^{c}\right)}>0,
\end{aligned}
$$

as $\theta_{s}<\tilde{\theta}^{c}<\theta^{c}$ and $\theta_{s} \in[-1,0)$. Hence $\lambda^{c}<1$.

For normal hours under certainty, $\theta=\bar{\theta}(z)$ and $f(z, \bar{\theta}(z))=1$. Hence $\lambda^{c}=f\left(z+\Delta^{c}, \theta^{c}\right)$. Accordingly, the size thus depends on $z$, as $\lambda^{c} \gtrless 1 \Longleftrightarrow \theta^{c} \lessgtr \bar{\theta}\left(z+\Delta^{c}\right)$. 


\section{Appendix C Expected profit maximization}

\section{C.1 Expected profit maximization}

Expected profits are given by

$$
E(\pi)=E\left(p a^{\alpha / \tau} n^{\alpha} h^{\alpha \gamma}\right)-w[z E(a) \bar{h}+E(a o(h))] n .
$$

Hours are set ex post to maximize profits, yielding (10) at interior solutions, or normal hours $\bar{h}$ for intermediate prices. As $\frac{\partial E(\pi)}{\partial h}=0$ at interior solutions and $\frac{\partial h}{\partial n}=0$ at normal hours, the first-order condition for employment can be written as

$$
0=\frac{\partial E(\pi)}{\partial n}=E\left(\alpha p a^{\alpha / \tau} n^{\alpha-1} h^{\alpha \gamma}\right)-w z E(a) \bar{h}-w E(a o(h) h) .
$$

Distinguishing between the tree possible regimes - short-time, normal hours and overtime - and substituting the corresponding demand for hours (10), this condition can be written as

$$
\begin{aligned}
0 & =\int_{0}^{1} \int_{0}^{\bar{p}\left(\theta_{s}\right)}\left\{(1-\gamma) \alpha^{\frac{1}{1-\alpha \gamma}}\left(\frac{\gamma}{\left(1+\theta_{s}\right) w}\right)^{\frac{\alpha \gamma}{1-\alpha \gamma}} p^{\frac{1}{1-\alpha \gamma}} a^{\frac{\alpha(1-\tau \gamma)}{\tau(1-\alpha \gamma)}} n^{-\frac{1-\alpha}{1-\alpha \gamma}}+\theta_{s} a w \bar{h}\right\} d F_{p}(p) d F_{a}(a) \\
& +\int_{0}^{1} \int_{\bar{p}\left(\theta_{s}\right)}^{\bar{p}\left(\theta_{o}\right)}\left\{\alpha p a^{\alpha / \tau} n^{\alpha-1} \bar{h}^{\alpha \gamma}-a w \bar{h}\right\} d F_{p}(p) d F_{a}(a) \\
& +\int_{0}^{1} \int_{\bar{p}\left(\theta_{o}\right)}^{\infty}\left\{(1-\gamma) \alpha^{\frac{1}{1-\alpha \gamma}}\left(\frac{\gamma}{\left(1+\theta_{o}\right) w}\right)^{\frac{\alpha \gamma}{1-\alpha \gamma}} p^{\frac{1}{1-\alpha \gamma}} a^{\frac{\alpha(1-\tau \gamma)}{\tau(1-\alpha \gamma)}} n^{-\frac{1-\alpha}{1-\alpha \gamma}}+\theta_{o} a w \bar{h}\right\} d F_{p}(p) d F_{a}(a) \\
& -w z E(a) \bar{h}
\end{aligned}
$$

To simplify, first define the virtual premium rate $\bar{\theta}$ that equates hours demand in (10) with standard hours, so

$$
1+\bar{\theta} \equiv \frac{\alpha \gamma p a^{(\alpha-\tau) / \tau} \bar{h}^{-(1-\alpha \gamma)} n^{-(1-\alpha)}}{w} .
$$

This premium is increasing in the price $p$, with $\bar{\theta}=\theta_{s}$ for $p=\bar{p}\left(\theta_{s}\right)$ and $\bar{\theta}=\theta_{o}$ for $p=\bar{p}\left(\theta_{o}\right)$. Moreover, $\frac{\partial \bar{\theta}}{\partial n}<0$. Using $\bar{\theta}$, the middle part of (C.2) can be written as

$$
\alpha p a^{\alpha / \tau} n^{\alpha-1} \bar{h}^{\alpha \gamma}-a w \bar{h}=(1-\gamma) \alpha^{\frac{1}{1-\alpha \gamma}}\left(\frac{\gamma}{(1+\bar{\theta}) w}\right)^{\frac{\alpha \gamma}{1-\alpha \gamma}} p^{\frac{1}{1-\alpha \gamma}} a^{\frac{\alpha(1-\tau \gamma)}{\bar{\tau}(1-\alpha \gamma)}} n^{-\frac{1-\alpha}{1-\alpha \gamma}}+\bar{\theta} a w \bar{h}
$$

and thus has the same structure as the expressions in the overtime or short-time regimes.

Next, define the virtual premium $\theta_{n}^{p}$ as a kind of weighted harmonic mean of $\theta_{o}, \theta_{s}$ and $\bar{\theta}$

$$
\begin{aligned}
& \left(1+\theta_{n}^{p}\right)^{-\frac{\alpha \gamma}{1-\alpha \gamma}} \equiv\left(1+\theta_{s}\right)^{-\frac{\alpha \gamma}{1-\alpha \gamma}} \int_{0}^{1} \int_{0}^{\bar{p}\left(\theta_{s}\right)} \frac{p^{\frac{1}{1-\alpha \gamma}} a^{\frac{\alpha(1-\tau \gamma)}{\tau(1-\alpha \gamma)}}}{E\left(p^{\frac{1}{1-\alpha \gamma}}\right) E\left(a^{\frac{\alpha(1-\tau \gamma)}{\tau(1-\alpha \gamma)}}\right)} d F_{p}(p) d F_{a}(a) \\
& +\int_{0}^{1} \int_{\bar{p}\left(\theta_{s}\right)}^{\bar{p}\left(\theta_{o}\right)}(1+\bar{\theta})^{-\frac{\alpha \gamma}{1-\alpha \gamma}} \frac{p^{\frac{1}{1-\alpha \gamma}} a^{\frac{\alpha(1-\tau \gamma)}{\tau(1-\alpha \gamma)}}}{E\left(p^{\frac{1}{1-\alpha \gamma}}\right) E\left(a^{\frac{\alpha(1-\tau \gamma)}{\tau(1-\alpha \gamma)}}\right)} d F_{p}(p) d F_{a}(a) \\
& +\left(1+\theta_{o}\right)^{-\frac{\alpha \gamma}{1-\alpha \gamma}} \int_{0}^{1} \int_{\bar{p}\left(\theta_{o}\right)}^{\infty} \frac{p^{\frac{1}{1-\alpha \gamma}} a^{\frac{\alpha(1-\tau \gamma)}{\tau(1-\alpha \gamma)}}}{E\left(p^{\frac{1}{1-\alpha \gamma}}\right) E\left(a^{\frac{\alpha(1-\tau \gamma)}{\tau(1-\alpha \gamma)}}\right)} d F_{p}(p) d F_{a}(a)
\end{aligned}
$$


As $\frac{\partial \theta_{n}^{p}}{\partial n}<0,\left.\theta_{n}^{p}\right|_{n=0}=\theta_{o}$ and $\lim _{n \rightarrow \infty} \theta_{n}^{p}=\theta_{s}$, this premium satisfies $\theta_{n}^{p} \in\left(\theta_{s}, \theta_{o}\right)$. Moreover, it is increasing in the undelying premia, $\frac{\partial \theta_{n}^{p}}{\partial \theta_{s}}>0$ and $\frac{\partial \theta_{n}^{p}}{\partial \theta_{o}}>0$.

Third, define another virtual premium $\tilde{\theta}^{p}$ as a weighted arithmetic mean of $\theta_{o}, \theta_{s}$ and $\bar{\theta}_{n}$

$$
\begin{aligned}
\tilde{\theta}^{p} & \equiv \theta_{s} \int_{0}^{1} \int_{0}^{\bar{p}\left(\theta_{s}\right)} \frac{a}{E(a)} d F_{p}(p) d F_{a}(a)+\int_{0}^{1} \int_{\bar{p}\left(\theta_{s}\right)}^{\bar{p}\left(\theta_{o}\right)} \bar{\theta} \frac{a}{E(a)} d F_{p}(p) d F_{a}(a) \\
& +\theta_{o} \int_{0}^{1} \int_{\bar{p}\left(\theta_{o}\right)}^{\infty} \frac{a}{E(a)} d F_{p}(p) d F_{a}(a) .
\end{aligned}
$$

Again, it is easily established that $\tilde{\theta}^{p} \in\left(\theta_{s}, \theta_{o}\right)$ and that $\tilde{\theta}^{p}$ is increasing in $\theta_{o}$ and $\theta_{s}$. Let $\Delta_{n}^{p} \equiv \theta_{n}^{p}-\tilde{\theta}^{p}$ denote the difference between both premia. The numerical simulations suggest that $\Delta_{n}^{p}>0$.

Using these virtual premia, equation (C.2) can be written as

$$
(1-\gamma) \alpha^{\frac{1}{1-\alpha \gamma}}\left(\frac{\gamma}{\left(1+\theta_{n}^{p}\right) w}\right)^{\frac{\alpha \gamma}{1-\alpha \gamma}} E\left(p^{\frac{1}{1-\alpha \gamma}} a^{\frac{\alpha(1-\tau \gamma)}{\tau(1-\alpha \gamma)}}\right) n^{-\frac{1-\alpha}{1-\alpha \gamma}}=w\left(z-\tilde{\theta}^{p}\right) E(a) \bar{h} .
$$

So the (implicit) solution for employment can we written as

$$
n_{u}^{p^{1-\alpha}}=\frac{\alpha \gamma E\left(p^{\frac{1}{1-\alpha \gamma}}\right)^{1-\alpha \gamma} E\left(a^{\frac{\alpha(1-\tau \gamma)}{\tau(1-\alpha \gamma)}}\right)^{1-\alpha \gamma}}{\left(1+\theta_{n}^{p}\right) w E(a)^{1-\alpha \gamma} \bar{h}^{1-\alpha \gamma} f\left(z+\Delta_{n}^{p}, \theta_{n}^{p}\right)^{1-\alpha \gamma}} .
$$

For expected hours, substitute (C.3) in (10) and take expectations to get

$$
E(h)=\delta_{h}^{p} f\left(z+\Delta_{n}^{p}, \theta_{n}^{p}\right) \bar{h} \frac{\left(1+\theta_{n}^{p}\right)^{1 /(1-\alpha \gamma)}}{E\left(p^{1 /(1-\alpha \gamma)}\right) E\left(a^{\frac{\alpha-\tau}{\tau(1-\alpha \gamma)}}\right)} E\left(\left(\frac{p a^{(\alpha-\tau) / \tau}}{1+\theta}\right)^{1 /(1-\alpha \gamma)}\right)
$$

For the last part of this expression, define the virtual premium $\theta_{h}^{p}$ as another weighted harmonic mean of $\theta_{o}, \theta_{s}$ and $\bar{\theta}_{n}$

$$
\begin{aligned}
\left(1+\theta_{h}^{p}\right)^{-\frac{1}{1-\alpha \gamma}} & \equiv\left(1+\theta_{s}\right)^{-\frac{1}{1-\alpha \gamma}} \int_{0}^{1} \int_{0}^{\bar{p}\left(\theta_{s}\right)} \frac{p^{\frac{1}{1-\alpha \gamma}} a^{\frac{\alpha-\tau}{\tau(1-\alpha \gamma)}}}{E\left(p^{\frac{1}{1-\alpha \gamma}}\right) E\left(a^{\frac{\alpha-\tau}{\tau(1-\alpha \gamma)}}\right)} d F_{p}(p) d F_{a}(a) \\
& +\int_{0}^{1} \int_{\bar{p}\left(\theta_{s}\right)}^{\bar{p}\left(\theta_{o}\right)}(1+\bar{\theta})^{-\frac{1}{1-\alpha \gamma}} \frac{p^{\frac{1}{1-\alpha \gamma}} a^{\frac{\alpha-\tau}{\tau(1-\alpha \gamma)}}}{E\left(p^{\frac{1}{1-\alpha \gamma}}\right) E\left(a^{\frac{\alpha-\tau}{\tau(1-\alpha \gamma)}}\right)} d F_{p}(p) d F_{a}(a) \\
& +\left(1+\theta_{o}\right)^{-\frac{1}{1-\alpha \gamma}} \int_{0}^{1} \int_{\bar{p}\left(\theta_{o}\right)}^{\infty} \frac{p^{\frac{1}{1-\alpha \gamma}} a^{\frac{\alpha-\tau}{\tau(1-\alpha \gamma)}}}{E\left(p^{\frac{1}{1-\alpha \gamma}}\right) E\left(a^{\frac{\alpha-\tau}{\tau(1-\alpha \gamma)}}\right)} d F_{p}(p) d F_{a}(a) .
\end{aligned}
$$

As $\frac{\partial \theta_{h}^{p}}{\partial n}<0,\left.\theta_{h}^{p}\right|_{n=0}=\theta_{o}$ and $\lim _{n \rightarrow \infty} \theta_{h}^{p}=\theta_{s}$, the premium satisfies $\theta_{h}^{p} \in\left(\theta_{s}, \theta_{o}\right)$. Using $\theta_{h}^{p}$, expected hours can be written as

$$
E(h)=\delta_{h}^{p} f\left(z+\Delta_{n}^{p}, \theta_{n}^{p}\right) \bar{h}\left(\frac{1+\theta_{n}^{p}}{1+\theta_{h}^{p}}\right)^{1 /(1-\alpha \gamma)}
$$

Furthermore, defining

$$
1+\theta^{p} \equiv\left(1+\theta_{h}^{p}\right)^{1 /(1-\alpha \gamma)}\left(1+\theta_{n}^{p}\right)^{-\alpha \gamma /(1-\alpha \gamma)}
$$


and

$$
\Delta^{p} \equiv \theta^{p}-\tilde{\theta}^{p}
$$

expected hours can finally be written as

$$
E(h)=\delta_{h}^{p} f\left(z+\Delta^{p}, \theta^{p}\right) \bar{h} .
$$

Again, $\left.\theta^{p}\right|_{n=0}=\theta_{o}$ and $\lim _{n \rightarrow \infty} \theta^{p}=\theta_{s}$. However, I have not been able to prove that $\theta^{p}$ is monotonously decreasing in $n$. Numerical simulations suggests this to be the case. Moreover, specifically, the numerical simulations suggest that $\theta_{n}^{p}>\theta_{h}^{p}>\theta^{p}>\tilde{\theta}^{p}$. As a result, $\Delta_{n}^{p}>$ $\Delta^{p}>0$.

Finally, to measure the premium effects on employment, compare equation (C.3) with (11) to define

$$
\lambda_{n}^{p} \equiv\left[\frac{1+\theta}{1+\theta_{n}^{p}}\left(\frac{f(z, \theta)}{f\left(z+\Delta_{n}^{p}, \theta_{n}^{p}\right)}\right)^{1-\alpha \gamma}\right]^{1 /(1-\alpha)} .
$$

Using the functional form of $f(z, \theta)$ and the definition of $\theta^{p}$ and $\Delta^{p}$ this can be rewritten as

$$
\lambda_{n}^{p} \equiv\left[\frac{1+\theta}{1+\theta_{h}^{p}} \lambda_{h}^{p^{-(1-\alpha \gamma)}}\right]^{1 /(1-\alpha)} .
$$

